\title{
Development of the Parthenocarpic Eggplant Cultivar 'Anominori'
}

\author{
Takeo SAITO", Tatemi YOSHIDA ${ }^{1,2}$, Shinji MONMA ${ }^{1,3}$, \\ Hiroshi MATSUNAGA ${ }^{1}$, Takanori SATO ${ }^{1,4}$, Atsushi SAITO ${ }^{1}$ and \\ Tomohiro YAMADA ${ }^{1}$ \\ ${ }^{1}$ Vegetable Breeding Research Team, National Institute of Vegetable and Tea Science, \\ National Agriculture and Food Research Organization (NARO) (Tsu, Mie 514-2392, Japan)
}

\begin{abstract}
Using pollinator insects or treating flowers with phytohormones is necessary for stable fruit setting in forcing culture of eggplant using plastic houses. However, these means are costly and/or labor-intensive. Use of parthenocarpic cultivars is considered to be the most cost-effective solution for stable fruit setting under sub-optimal environmental conditions such as lower temperature in forcing culture. 'Anominori', a parthenocarpic eggplant cultivar, was developed by the National Institute of Vegetable and Tea Science in 2006. This cultivar is the $F_{1}$ hybrid between two parthenocarpic inbred lines, 'AE-P08' and 'AE-P01'. 'AE-P08' was selected from the cross between an $\mathrm{F}_{3}$ plant derived from 'Nakate Shinkuro' $\times$ 'Talina' and an $\mathrm{F}_{4}$ plant derived from 'Talina' $\times$ 'Nasu Chuukanbohon Nou 1'. 'AE-P01' was selected from the cross between 'Talina' and 'Nasu Chuukanbohon Nou 1'. 'Anominori' can produce sufficient yields for commercial use without treating with phytohormones or using pollinator insects in forcing culture. The plant characteristics of 'Anominori' are the following: high plant height, long internode, thick stem and large leaves. The fruit of 'Anominori' at harvest stage is long egg-shaped and glossy dark purple. The flesh of fruit is very dense.
\end{abstract}

Discipline: Plant breeding

Additional key words: breeding, parthenocarpy, Solanum melongena

\section{Introduction}

Using pollinator insects ${ }^{3}$ or treating flowers with phytohormones ${ }^{7}$ is necessary for stable fruit setting in forcing culture of eggplant using plastic houses. However, these means are costly and/or labor-intensive; it is necessary to keep a plastic house warm for pollinator insects to be active or treating flowers with phytohormones takes about $25-30 \%$ of total working hours required for eggplant forcing culture. Use of parthenocarpic cultivars is the most cost-effective solution for stable fruit setting under sub-optimal environmental conditions such as lower temperature in forcing culture.

Several parthenocarpic eggplant cultivars have been bred in Europe. Moreover, transgenic parthenocarpic eggplants have been produced and evaluated under plastic houses and open field cultivation ${ }^{1,2,4,5}$. However, it was very difficult to introduce and distribute these cultivars to Japan because of their undesirable agricultural characteristics for Japanese people such as green calyx, reddish purple fruit and low yield.

In Japan, we started the breeding program to develop a parthenocarpic eggplant cultivar acceptable to Japanese consumers in 1994 using a European parthenocarpic cultivar 'Talina' kindly provided by Dr. Giuseppe Leonardo Rotino, Research Institute for Vegetable Crops, Italy. 'Anominori', a parthenocarpic eggplant cultivar which has glossy dark purple calyx and fruit preferred by Japanese consumers was developed at the National Institute

\footnotetext{
Present address:

${ }^{2}$ Taketoyo Vegetable Research Station, National Institute of Vegetable and Tea Science, NARO (Chita, Aichi 470-2351, Japan)

${ }^{3}$ Bio-Oriented Technology Research Advancement Institute, NARO (Minato-ku, Tokyo 105-0001, Japan)

${ }^{4}$ Department of Planning and General Administration, National Institute of Vegetable and Tea Science, NARO (Tsu, Mie 5142392, Japan)
}

*Corresponding author: e-mail romario@affrc.go.jp

Received 12 November 2007; accepted 16 July 2008. 
of Vegetable and Tea Science (NIVTS) in 2006. Here we introduce the procedure of development and characteristics of 'Anominori'.

\section{Materials and methods}

\section{Development of 'Anominori'}

'Talina', a commercial parthenocarpic $\mathrm{F}_{1}$ hybrid released by Sluis \& Groot Co. Ltd. and widely cultivated in Italy, was used as a breeding material for parthenocarpy (Fig. 1). 'Talina' was crossed to 'Nakate Shinkuro', a Japanese cultivar and also crossed to 'Nasu Chuukanbohon Nou 1', a parental line bred by NIVTS in 1994. Individuals having fruit quality favorable for Japanese people such as glossy dark purple calyx and fruit and exhibiting high parthenocarpic ability had been selected from the progenies. 'AE-P08' was selected from the cross between an $F_{3}$ plant derived from 'Nakate Shinkuro' $\times$ 'Talina' and an $\mathrm{F}_{4}$ plant from 'Talina' $\times$ 'Nasu Chuukanbohon Nou 1'. 'AE-P01' was selected from 'Talina' $\times$ 'Nasu Chuukanbohon Nou 1'. The $F_{1}$ hybrid between two parthenocarpic inbred lines, 'AE-P08' and 'AE-P01', was named 'Anominori'.

\section{Characteristics of 'Anominori'}

Performance of 'Anominori' was tested in forcing culture in 2004 and in open field culture in 2005 at NIVTS using two Japanese leading cultivars, 'Senryou Nigou' (TAKII \& CO., Ltd.) and 'Chikuyou' (TAKII \& CO., Ltd.) as standard cultivars. Yield of marketable fruits and characteristics of plant and fruit were evaluated.

\section{Parthenocarpy in 'Anominori'}

(1) Experiment 1. Forcing culture by training three main branches

Ten plants each of 'Anominori', 'Senryou Nigou' and 'Chikuyou' were tested for performance. A steel frame greenhouse, $6 \mathrm{~m}$ wide and $20 \mathrm{~m}$ long, was covered by plastic polyethylene film. Seeds were sown on $20 \mathrm{Au}-$ gust 2006. Plantlets at ten leaves stage were transplanted to the field in raised beds on 5 October. Plants were laid out $0.6 \mathrm{~m}$ apart in rows with an inter-row distance of 1.2 m. Three main branches were trained. Phytohormones were not treated during the experiment. Styles of at least five flower buds per each plant were excised from October to November. Percentage of parthenocarpy was calculated as the ratio of the number of fruits grown to marketable size to that of flower buds with the style excised.

(2) Experiment 2. Forcing culture by training one main branch

Six plants each of 'Anominori', 'AE-P08', 'AE-P01', 'Senryou Nigou', 'Chikuyou’, ‘Nakate Shinkuro’, ‘Talina 2/1' (a parthenocarpic doubled haploid line of 'Talina', provided by Dr. G. L. Rotino in 1994), and 'Mileda' (Novartis Seeds B. V.) were tested for performance. A steel frame greenhouse, $8 \mathrm{~m}$ wide and $20 \mathrm{~m}$ long, was covered by F-CLEAN® (ASAHI GLASS CO., LTD) film. Seeds were sown on 20 August 2006. Plantlets at ten leaves stage were transplanted to the field in raised beds on 5 October. Plants were laid out $0.4 \mathrm{~m}$ apart in four double rows, with an intra-row distance of $0.6 \mathrm{~m}$ and an interrow distance of $1.8 \mathrm{~m}$. A main branch was trained. Phytohormones were not treated during the experiment. Styles of at least five flower buds per each plant were excised from October to November. Percentage of parthenocarpy was calculated as the ratio of the number of fruits grown to marketable size to that of flower buds with the style excised.

(3) Experiment 3. Summer cultivation by training three main branches

A steel frame greenhouse, $6 \mathrm{~m}$ wide and $20 \mathrm{~m}$ long, was covered by plastic polyethylene film. Seeds were sown on 21 August 2006. Plantlets were transplanted to the field in raised beds on 1 November. Plants were laid out $0.6 \mathrm{~m}$ apart in rows with an inter-row distance of 1.2 m. Three main branches were trained. Phytohormones were not treated during the experiment. Styles of at least five flower buds per each plant were excised from June to July in 2007. The percentage of parthenocarpic fruits was calculated as the ratio of the number of fruits grown to marketable size to that of flower buds with the style ex-

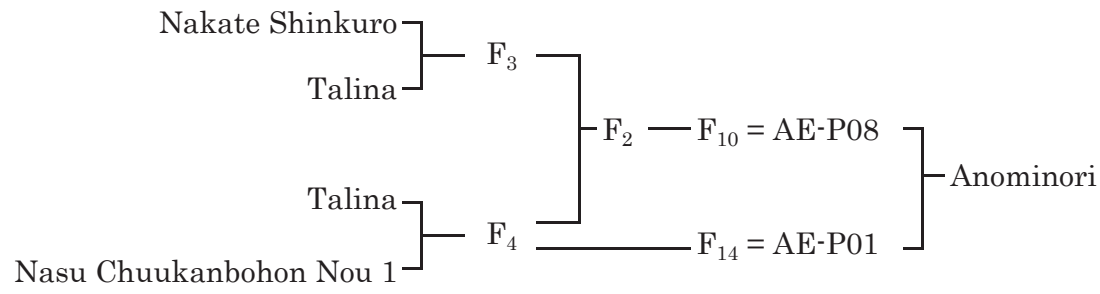

Fig. 1. The pedigree of 'Anominori' 
cised.

\section{Results and discussion}

'Anominori' is the $\mathrm{F}_{1}$ hybrid between two parthenocarpic inbred lines, 'AE-P08' and 'AE-P01' (Figs. 1 \& 2), and was registered as 'Nasu Nourin Kou 4' by the Ministry of Agriculture, Forestry and Fisheries of Japan in 2006.

The plant morphological characteristics of 'Anominori' are the following: high plant height, long internode, thick stem, and long petiole (Table 1). The fruit of 'Anom- inori' at harvest stage is long egg-shaped and glossy dark purple (Table 2 \& Fig. 2). The flesh of fruit is very dense. The yield of marketable fruits of 'Anominori' was 456 $\mathrm{kg} / \mathrm{a}$, which is adequate for practical use in forcing culture, compared to 67 and $151 \mathrm{~kg} / \mathrm{a}$ in 'Senryou Nigou' and 'Chikuyou', respectively (Table 3). On the other hand, the yields of 'Anominori' were lower than those of 'Senryou Nigou' and 'Chikuyou' in open field culture both in 2004 and in 2005 (Table 3).

(1) Experiment 1. Forcing culture by training three main branches

In order to compare the parthenocarpic ability

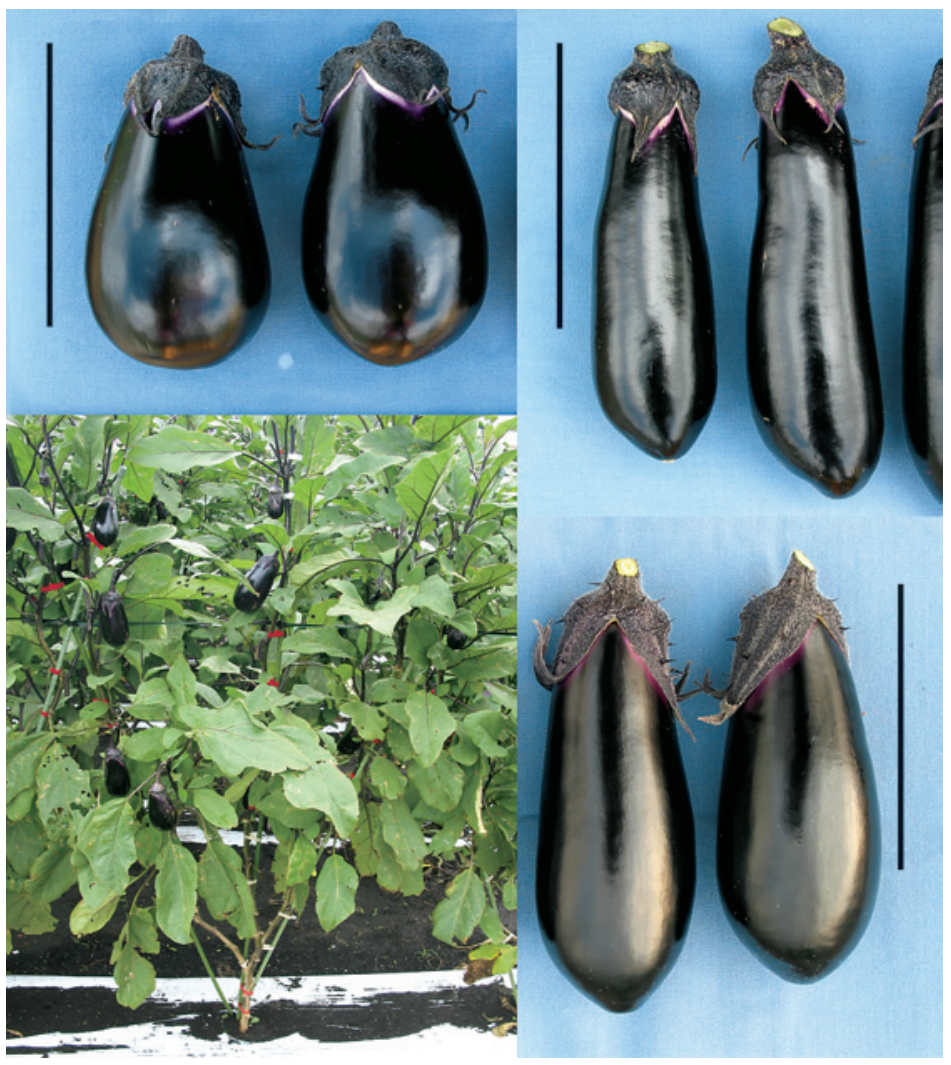

Fig. 2. Fruits of 'AE-P08' (upper left), ‘AE-P01' (upper right), ‘Anominori’ (lower right) and plants of 'Anominori' (lower left) Each bar is $10 \mathrm{~cm}$.

Table 1. Plant characteristics of 'Anominori'

\begin{tabular}{lllllll}
\hline \hline Cultivar & $\begin{array}{l}\text { Plant } \\
\text { height }\end{array}$ & $\begin{array}{l}\text { Internode } \\
\text { length }\end{array}$ & $\begin{array}{l}\text { Stem } \\
\text { thickness }\end{array}$ & $\begin{array}{l}\text { Stem } \\
\text { color }\end{array}$ & $\begin{array}{l}\text { Petiole } \\
\text { length }\end{array}$ & $\begin{array}{l}\text { Plant } \\
\text { branching }\end{array}$ \\
\hline Anominori & slightly tall & slightly long & thick & purple & slightly long & slightly weak \\
Senryou Nigou & intermediate & intermediate & intermediate & purple & intermediate & slightly strong \\
Chikuyou & tall & slightly short & slightly thick & purple & slightly long & slightly strong \\
\hline
\end{tabular}


Table 2. Marketable fruit of 'Anominori'

\begin{tabular}{|c|c|c|c|c|c|c|c|c|}
\hline \multirow{2}{*}{ Cultivar } & \multicolumn{2}{|c|}{ Length } & \multicolumn{2}{|c|}{ Diameter } & \multicolumn{2}{|c|}{ Weight } & \multirow{2}{*}{ Shape } & \multirow{2}{*}{ Color of calyx } \\
\hline & $(\mathrm{mm})$ & $\mathrm{SE}$ & $(\mathrm{mm})$ & SE & (g) & $\mathrm{SE}$ & & \\
\hline Anominori & 138.3 & 9.3 & 55.0 & 2.9 & 119.2 & 4.1 & long egg-shaped & purple-black \\
\hline Senryou Nigou & 143.0 & 2.1 & 48.0 & 1.0 & 102.1 & 3.3 & long egg-shaped & purple-black \\
\hline Chikuyou & 174.0 & 8.7 & 44.7 & 0.3 & 102.7 & 3.5 & slightly elongated & purple-black \\
\hline
\end{tabular}

Table 3. Yield of 'Anominori'

\begin{tabular}{lccc}
\hline \hline \multirow{2}{*}{ Cultivar } & \multicolumn{3}{c}{ Yield of marketable fruits (kg/a) } \\
\cline { 2 - 4 } & Forcing culture in 2004 & Open field culture in 2004 & Open field culture in 2005 \\
\hline Anominori & 456 & 908 & 784 \\
Senryou Nigou & 67 & 1,021 & 843 \\
Chikuyou & 151 & 1,102 & 929 \\
\hline
\end{tabular}

No cultivars were treated with phytohormones.

Fruits were harvested from 25 October 2004 to 22 March 2005 in forcing culture of 2004, from 23 June to 29 September in open field culture of 2004, and from 6 June to 30 September in open field culture of 2005.

Table 4. Parthenocarpy in 'Anominori'

\begin{tabular}{|c|c|c|c|c|c|c|}
\hline \multirow[t]{2}{*}{ Cultivar } & \multicolumn{2}{|c|}{ Abscised flowers } & \multicolumn{2}{|c|}{ Malformed fruits } & \multicolumn{2}{|c|}{ Parthenocarpic fruits } \\
\hline & (\%) & SE & $(\%)$ & SE & $(\%)$ & SE \\
\hline Anominori & 11.3 & 2.8 & 4.0 & 4.0 & 84.8 & 4.8 \\
\hline Senryou Nigou & 31.7 & 4.1 & 68.3 & 4.1 & 0.0 & 0.0 \\
\hline Chikuyou & 51.9 & 5.5 & 47.0 & 5.9 & 1.1 & 1.1 \\
\hline
\end{tabular}

Parcentages of abscised flowers, malformed fruits and parthenocarpic fruits were calculated as the ratio of numbers of abscised flowers, malformed fruits and fruits grown to marketable size to that of flower buds with the style excised.

Table 5. Comparison of parthenocarpic ability in some eggplant cultivars

\begin{tabular}{|c|c|c|c|c|c|c|}
\hline \multirow[t]{2}{*}{ Cultivar } & \multicolumn{2}{|c|}{ Abscised flowers } & \multicolumn{2}{|c|}{ Malformed fruits } & \multicolumn{2}{|c|}{ Parthenocarpic fruits } \\
\hline & (\%) & SE & $(\%)$ & $\mathrm{SE}$ & $(\%)$ & SE \\
\hline Anominori & 45.0 & 12.6 & 0.0 & 0.0 & 55.0 & 12.6 \\
\hline AE-P08 & 40.0 & 11.0 & 0.0 & 0.0 & 60.0 & 11.0 \\
\hline AE-P01 & 42.0 & 9.2 & 0.0 & 0.0 & 58.0 & 9.2 \\
\hline Mileda & 100.0 & 0.0 & 0.0 & 0.0 & 0.0 & 0.0 \\
\hline Talina 2/1 & 100.0 & 0.0 & 0.0 & 0.0 & 0.0 & 0.0 \\
\hline Senryou Nigou & 95.0 & 5.0 & 5.0 & 5.0 & 0.0 & 0.0 \\
\hline Chikuyou & 80.0 & 8.2 & 20.0 & 8.2 & 0.0 & 0.0 \\
\hline Nakate Shinkuro & 90.0 & 10.0 & 10.0 & 10.0 & 0.0 & 0.0 \\
\hline
\end{tabular}

Parcentages of abscised flowers, malformed fruits and parthenocarpic fruits were calculated as the ratio of numbers of abscised flowers, malformed fruits and fruits grown to marketable size to that of flower buds with the style excised. 
among three cultivars, the development of fruits after excision of styles was observed. Three patterns were observed: flower abscission, malformed fruit set and parthenocarpic fruit development. The percentage of parthenocarpic fruits was $84.8 \%$ in 'Anominori', but 0.0 and $1.1 \%$ in 'Senryou Nigou' and 'Chikuyou' (Table 4). On the other hand, the number of flowers abscised and that of malformed fruits were higher in 'Senryou Nigou' and 'Chikuyou' than in 'Anominori'.

(2) Experiment 2. Forcing culture by training a main branch

Parthenocarpic fruits of marketable weight and size were produced from 55.0, 60.7 and 58.0\% of flower buds after excision of styles in 'Anominori', 'AE-P08' and 'AEP01', respectively (Table 5). However, no fruits of marketable size set in European parthenocarpic cultivars, 'Mileda' or 'Talina 2/1' (Table 5). No fruits of marketable size were also produced in non-parthenocarpic 'Senryou Nigou', 'Chikuyou' or 'Nakate Shinkuro'. The reason why the expression of parthenocarpy in 'Anominori' was weaker in experiment 2 than in experiment 1 is unknown. It might be affected by culture conditions, methods of training branches, temperature, etc.

\section{(3) Experiment 3. Summer cultivation by training three main branches}

Parthenocarpic fruits of marketable weight and size were produced from 10\% (39/381) of flower buds after excision of styles in 'Anominori' under the summer conditions. It was thought to be difficult to express parthenocarpic trait under hot conditions. This does not mean that 'Anominori' is not suitable for summer cultivation in Japan because fertilized fruits of 'Anominori' can be produced in summer season (Table 3).

The parthenocarpic eggplant cultivars so far available still need phytohormone applications to produce fruits of marketable size in Europe ${ }^{2}$. Also in our results, the European parthenocarpic cultivars, 'Talina 2/1' and 'Mileda' could not produce commercial fruits in forcing culture, while 'Anominori' could produce sufficient yields. It may be possible that 'Anominori' can produce sufficient yields even in European winter conditions. Although the European parthenocarpic cultivars seemed to have high ability to elongate fruits once set without pollination, they have low ability to set fruits. By contrast, Japanese cultivars have high ability to set fruits without pollination but low ability to elongate the fruits. 'Anominori' is thought to have both these abilities. Now we are trying to breed a new parthenocarpic and perfectly seedless cultivar using cytoplasmic male sterility ${ }^{6}$.

\section{Acknowledgment}

We thank Dr. G. L. Rotino for kindly providing 'Talina' and 'Talina 2/1' seeds.

\section{References}

1. Acciarri, N. et al. (2002) Genetically modified parthenocarpic eggplants: improved fruit productivity under both plastic house and open field cultivation. BMC Biotechnol., 2, 4.

2. Donzella, G., Spena, A. \& Rotino, G. L. (2000) Transgenic parthenocarpic eggplants: superior germplasm for increased winter production. Mol. Breed., 6, 79-86.

3. Fernandez-Munoz, R., Cuartero, J. \& Gomez-Guillamon, M. L. (1995) Efficiency of bumble bees on the yield and quality of eggplant and tomato grown in unheated greenhouse. Acta Hortic., 412, 268-274.

4. Maestrelli, A. et al. (2003) Freezing effect on some quality parameters of transgenic parthenocarpic eggplants. $J$. Food Eng., 56, 285-287.

5. Rotino, G. L. et al. (1997) Genetic engineering of parthenocarpic plants. Nat. Biotechnol., 15, 1398-1401.

6. Saito, T., Yamada, T. \& Saito, A. (2005) A novel source of cytoplasmic male sterility and fertility restoration gene in eggplant (Solanum melongena L.). In $10^{\text {th }}$ International Congress of SABRAO, Abstracts, G-22.

7. Sarma, C. M. \& Barman, T. S. (1997) Production of parthenocarpic fruits in brinjal (Solanum melongena L.) by the application of $\beta$-napthoxyacetic acid ( $\beta$-NOA). Indian $J$. Hortic., 34, 422-425. 